\title{
Citas, préstamos y transformaciones en la levedad del hibridismo de Sarah Ruhl
}

\section{Ana Fernández-Caparrós Turina}

\section{(2) OpenEdition}

1 Journals

Edición electrónica

URL: https://journals.openedition.org/cher/2879

DOI: $10.4000 /$ cher.2879

ISSN: 2803-5992

\section{Editor}

Presses universitaires de Strasbourg

\section{Edición impresa}

Fecha de publicación: 27 junio 2017

Paginación: 98-107

ISBN: 978-2-86820-961-0

ISSN: 1968-035X

\section{Referencia electrónica}

Ana Fernández-Caparrós Turina, «Citas, préstamos y transformaciones en la levedad del hibridismo de Sarah Ruhl», reCHERches [En línea], 18 | 2017, Publicado el 01 diciembre 2021, consultado el 19 diciembre 2021. URL: http://journals.openedition.org/cher/2879; DOI: https://doi.org/10.4000/cher 2879

\section{cc) (i) (2)}

Ce(tte) œuvre est mise à disposition selon les termes de la Licence Creative Commons Attribution -

Pas d'Utilisation Commerciale - Partage dans les Mêmes Conditions 4.0 International. 


\title{
Citas, préstamos y transformaciones en la levedad del hibridismo de Sarah Ruhl
}

\author{
Ana Fernández-Caparrós Turina*
}

\section{El hibridismo de Sarah Ruhl}

Uno de los fenómenos de mayor interés en el ámbito de la dramaturgia estadounidense de la primera década del siglo veintiuno ha sido la emergencia de un influyente debate crítico sobre la falta de equidad entre hombres y mujeres en el teatro -y más concretamente sobre la persistente dificultad para las dramaturgas de ver sus obras producidas incluso en circuitos alternativos- a la vez que se reconocían el éxito y el papel cada vez más importante que estas están teniendo tanto en los circuitos comerciales como en los alternativos, a pesar de las condiciones adversas ${ }^{1}$. De hecho, puede que la figura más sobresaliente del teatro norteamericano más reciente sea la de una mujer menuda y discreta, Sarah Ruhl, a quien no le faltan méritos para ello. Desde 2002 ha estrenado doce obras, ha ganado numerosos premios (entre ellos una beca de excelencia MacArthur Genius Award en 2006, dotada con medio millón de dólares), y cuatro de sus obras han estado regularmente en las últimas temporadas entre las diez más producidas en los más de 500 teatros miembros de la asociación nacional Theatre Communications Group: en la temporada 2007-08 The Clean

* Profesora del Departamento de Filología inglesa y alemana de la Universidad de Valencia y especialista en teatro norteamericano contemporáneo.

1 El documento más importante en la denuncia de esta situación fue el informe elaborado por Susan Jonas y Suzanne Bennet en 2002, resultado de una investigación de tres años promovida y financiada por el Programa de teatro de la concejalía de las artes del estado de Nueva York. Siete años más tarde, la dramaturga Marsha Norman (2009) se lamentaba de la persistencia de la infrarrepresentación de las mujeres declarando que la estadística de un $83 \%$ de las obras producidas anualmente escritas por hombres apenas había variado. Desde el año 2000, solo cuatro mujeres han recibido un premio Pulitzer de teatro: Suzan-Lori Parks en 2004, Lynn Nottage en 2009, Quiara Alegría Hudes en 2012 y Annie Baker en 2014. 
House (2004) fue la segunda obra más producida, mientras que Eurydice (2003) ocuparía la quinta posición en la temporada siguiente; en 2009-2010 Dead Man's Cell Phone (2007) ocupó el segundo lugar e In the Next Room, or the Vibrator Play (2009) fue la séptima obra más producida en 2010-2011 y la tercera en la temporada siguiente (Atkis Durham 2013: 4).

Si hay algo que, no obstante, merece una atención crítica perentoria, en el caso concreto del notorio éxito de Ruhl, no es tanto su condición de mujer al alcanzar tal relevancia en el panorama teatral, sino lo que este éxito implica dada la naturaleza misma de la obra de esta dramaturga nacida en Wilmette, Illinois, hace cuarenta y dos años. Nadie parece poner en duda que sus obras presentan un lenguaje poético y escénico propios para los que no parecía haber referentes o modelos claros en su país de origen. Por ello -ante la fascinación generada por personajes que se tornan en almendra en Melancholy Play, o la entrada a través de un ascensor lluvioso a un inframundo que «se asemeja más al mundo de Alicia en el País de las maravillas que al Hades»² (Ruhl 2006: 332), en Eurydicehay un sinfín de intentos de clasificar y definir estas piezas como fantasías poéticas, alucinatorias, surrealistas, imaginativas. En uno de los mejores retratos de la autora, publicado en The New Yorker, John Lahr (2008) dice de Ruhl que «escribe con un estilo sereno y cristalino sobre asuntos irracionales e invisibles. Es una fabuladora. Sus obras celebran lo que ella denomina 'el placer de las cosas aguzadas'» en un espacio a medio camino entre el mundo real y un estado de suspensión. Su artículo es casi una excepción entre abundantes crónicas y críticas periodísticas forzosamente sucintas y superficiales, y solo en los dos últimos años, con la publicación de los volúmenes de Al-Shamma (2011) y Atkis Durham (2013), la crítica académica comienza a responder del éxito comercial de la autora y a abordar con mayor rigor cuestiones relativas al peculiar hibridismo de su obra, su combinación de «teatro de vanguardia, con los clásicos griegos, la poesía, el realismo mágico, un toque de vaudeville y expresionismo alemán» (Goodman 2007).

El hibridismo de la obra de Ruhl puede resultar caprichoso, y tal vez lo sea. Ante este calificativo tan frecuente en la recepción de su obra, Ruhl ha respondido en un breve texto titulado "Why I Hate the Word Whimsy» (2013). Rastreando el origen etimológico de la palabra whimsy y su cognado whimwham -relacionado con un revoloteo o con dejar vagar a la mirada- Ruhl lamenta que se feminizara este último sentido y se trivializara así toda una escuela de fabulación estética: las obras de Shakespeare, explica, jamás recibirían el apelativo de caprichosas a pesar de invocar hadas y brujas, mientras que las de las escritoras más imaginativas son a menudo tildadas de triviales si muestran esas predilecciones.

Para interrogar la aparente veleidad de la obra dramática de Ruhl hay que tener en cuenta, precisamente, su diálogo con la obra shakespeareana, pero también

2 Esta y las sucesivas citas de fuentes primarias y secundarias en inglés son traducción de la autora del artículo, a menos que se indique lo contrario. 
su interrelación con otros textos contemporáneos, modernos y clásicos. Atender a los fenómenos de apropiación, repetición, cita y transformación se convierte así en estrategia fundamental para comprender que las meditadas relaciones intertextuales no son secundarias sino primordiales para la transgresión de los límites impuestos por la tradición escénica del realismo y definitorios de la singularidad del estilo de Ruhl dentro de la tradición dramática norteamericana. Es lo que me propongo demostrar en las siguientes páginas a través del análisis de voces y vías múltiples que confluyen en la comedia negra Dead Man's Cell Phone (El teléfono móvil de un hombre muerto). En esta la permutación e intersección con otros textos es más sutil y más compleja que en un caso de reinterpretación directa de un mito clásico como era Eurydice. Se trata, junto con Melancholy Play, del único texto dramático publicado de Ruhl al que anteceden citas literarias; aunque, a diferencia de esta última, en que las citas de The Anatomy of Melancholy (1632) de Robert Burton aluden directamente al tema dramático, en Dead Man las tres citas seleccionadas por la autora parecen tener un sentido más velado. Mi propósito en las páginas siguientes es investigar en primera instancia esas relaciones intertextuales explicitadas en el paratexto y partir, de hecho, de los márgenes textuales para abordar el encuentro con la alteridad subyacente al hibridismo. ¿Hay acaso en el espacio hermenéutico abierto por el encuentro (es decir, la cita) del texto dramático con las tres citas que lo anteceden, una promesa de sentido que nos permita esclarecer o al menos abordar las incertidumbres y la extrañeza generadas por lo que observamos como espectadores? Al remitir a una serie de fuentes en un reconocimiento de que estas fueron, asumimos, esenciales en el proceso creativo, las citas atestiguan al menos una parte de la compleja realidad múltiple y multiforme del texto. Sin embargo, ante una obra teatral, surge por otra parte la cuestión de la recepción de la misma en el teatro y por un público a la que en principio le son ajenas esas referencias, a menos que hayan tenido acceso al manuscrito o al texto publicado, lo cual es improbable antes y después del estreno de una pieza teatral. ¿En qué modo esa intertextualidad entendida como permutación y productividad -términos usados seminalmente por Kristeva (Orr 2003: 27)-, tiene lugar en el marco de la representación teatral?

\section{Citas en el espacio dramático}

Dead Man's Cell Phone comienza en un café casi vacío en el que Jean, una mujer de «cualidad insular, como si no quisiera ocupar espacio» (Ruhl 2007: 7), se encuentra repentinamente sola con un hombre inmóvil, sentado en la mesa de al lado, cuyo teléfono móvil suena incesantemente. En esta coyuntura, Jean decide contestar al teléfono del extraño y, al descubrir que Gordon ha fallecido, su inesperada reacción a continuación, y durante las seis escenas que componen el primer acto de la obra, es no desprenderse de ese teléfono móvil ajeno y fingir ser una compañera de trabajo del difunto con la misión incomprensible de permanecer conectada con este y poder así consolar a sus familiares en el duelo. 
Durante el primer acto, esta mujer de apariencia frágil entra en relación con los extravagantes parientes del muerto y da rienda suelta a su sentimental afán de confabulación inventando alguna historia reconfortante para cada uno de ellos sobre las últimas palabras pronunciadas por el misterioso Gordon, historias que estos aceptan con una cierta tensión tácita. Pese al inesperado desenlace romántico que pone fin al primer acto -cuando Jean y Dwight, hermano del difunto, se besan bajo una lluvia de tarjetas de papel repujado en una papeleríaun melancólico halo de misterio parece impregnar todo aquello que acontece sobre el escenario.

La primera cita que antecede al cuerpo de texto de Dead Man reproduce los primeros párrafos del capítulo tercero, "Las sombras de la noche», de Historia de Dos Ciudades de Charles Dickens, de la que se reproduce una parte en traducción de José María Méndez:

Merece la pena que nos detengamos a pensar en el hecho maravilloso de que toda criatura humana resulta para sus semejantes un profundo y arcano misterio. Cuando yo llego de noche a una gran ciudad, me sugiere solemnes consideraciones el que cada una de las casas que se apiñan en la oscuridad encierra su propio secreto; que cada una de sus habitaciones guarda un secreto también; que cada uno de los corazones que palpitan dentro de los centenares de miles de pechos que hay allí, encierra anhelos que constituyen un secreto para el corazón que tiene a su lado mismo (Dickens 1951: 1010).

La segunda cita remite a una fuente más antigua, del siglo xvir. Se trata de la última estrofa del poema de John Donne «The Undertaking» (La proeza), y que Purificación Ribes ha traducido así:

Proeza mayor has hecho que la de todos los héroes, y otra mayor surgirá,

la de guardarlo en secreto (Donne 1996: 277).

Por último, el tercer fragmento seleccionado por Ruhl proviene del libro homónimo sobre Hopper publicado por el poeta Mark Strand por primera vez en 1994:

En muchos cuadros de Hopper hay una espera aconteciendo...Son como personajes que se hubiesen quedado sin un papel que desempeñar, y ahora, atrapados en el espacio de su espera, deben hacerse compañía (2008: 57).

El extraño encuentro surgido de la invocación a Dickens, Donne y Strand no parece en un primer momento esclarecer de un modo unívoco lo presentado en el texto dramático, sino desestabilizar, diferir o multiplicar los sentidos y los modos de reaccionar ante la obra. Pero si la cita de Dickens, en particular, enfatiza la imposibilidad última de conocer el profundo y arcano misterio del otro, el imprevisible duelo más allá de lazos de parentesco y amistad en el que Jean se embarca desde el comienzo de la obra, parece estar movido por una fuerza opuesta, por un deseo incontenible de traspasar de facto los límites o las barreras (físicas, metafísicas, sociales) que dificultan ese encuentro con los otros. Como veremos, el modo en que en Dead Man's Cell Phone responde al diálogo 
intertextual abierto por las citas, es actuando sobre las cuestiones que estas plantean desde la praxis teatral entendida como apertura hacia la posibilidad.

Si atendemos por el momento a la cuestión de cómo trasponer esas citas literarias al espacio dramático, esto nos puede conducir ya por sendas interesantes. Las dos primeras son puestas en boca de personajes: la de Charles Dickens, tras la muerte de Gordon, en su funeral, y la segunda, en boca de Dwight al final de la representación. La tercera cita es llamativa porque ha determinado en casi la totalidad de las producciones una escenografía inspirada en la obra pictórica del pintor de Nueva York, pues hay, además, dentro de las «Notas para el director», en esta obra llena de silencio, momentos que la autora denomina «los momentos Edward Hopper» en los que, indica, «se trata de encontrar un simple gesto, por ejemplo, Jean mira hacia una ventana, vacila, y las luces cambian imperceptiblemente. Son sobre la figura solitaria dentro de un paisaje o una arquitectura, o sobre la sensación de sentirse solo dentro de o en relación a la modernidad» (Ruhl 2008: 103). Así, por ejemplo, viendo las fotografías de Joan Marcus del estreno de la obra en Nueva York en marzo de 2008, disponibles en la página web oficial de Sarah Ruhl, ${ }^{3}$ reconocemos, al contemplar la imagen de Marie-Louise Parker en el papel de Jean al inicio de la representación, una trasposición escénica clara de un cuadro emblemático de Edward Hopper, Automat, expuesto por primera vez en la segunda exposición individual del pintor estadounidense en la Rhein Gallery de Nueva York en 1927, y actualmente albergado en el Des Moines Art Center de Iowa. Anne Bogart, influyente cofundadora de la SITI Company y directora de este montaje, ha confirmado que sus cuadros fueron «una enorme influencia... de hecho central» en el plano visual (2012).

El lienzo Automat presenta uno de los elementos recurrentes en la obra de Hopper cuya transposición es visible en los primeros montajes de Dead Man's Cell Phone en Washington y Nueva York, que fueron supervisados por la misma Ruhl (Bogart 2012): un fondo oscuro, casi amenazante. En Automat, este resulta muy inquietante porque la ventana detrás de la mujer pensativa tomando café solo refleja la fila de luces gemelas que se alejan por el techo del bar de del autoservicio, pero no a ella; si lo que refleja es verdad, sugiere Strand (2008: 78), entonces la escena tiene lugar en el limbo, y la mujer pintada es tan solo una ilusión, la ilusión de Hopper. La trasposición de ese fondo oscuro al espacio escénico de Dead Man, unido al extraño comportamiento de la sentimental Jean, un personaje que es un enigma hasta el final de la representación, podría hacer que nos cuestionáramos si ella también, como la figura solitaria hopperiana, se encuentra en un limbo. Curiosamente, lo que ocurre en la segunda parte de la obra nos puede hacer pensar que sí, pues Jean, de quien Mrs. Gottlieb teme que desaparezca en el éter (Ruhl 2008: 42), literalmente lo hace: tras una melancólica primera parte, el teléfono que esta mujer porta en sus manos la llevará primero hasta Sudáfrica, y a continuación hasta el más allá, donde la protagonista tendrá

3 Cf. http://www.sarahruhlplaywright.com/image/info/56/. 
por fin ocasión de conversar con el misterioso Gordon. Este, el difunto, aparece tras el intermedio, y como apunta Rainer (2006: x), los fantasmas aparecen siempre que hay secretos que han quedado sepultados con ellos en el tiempo: su monólogo sobre el último día de su vida revela que se dedicaba al comercio ilegal de órganos. Cuando Jean por fin lo descubre, su obstinado afán por enmendar la «falta de culpa metafísica» (Ruhl 2008: 32) de la que carecía el carismático Gordon, según su madre, la hace aventurarse en la osadía de inmiscuirse en el turbio negocio y tratar de intercambiar en el aeropuerto de Johannesburgo un riñón sano por una lámpara en forma de riñón. El uso de esta metáfora visual es efectivo, pues apenas Jean recibe un fuerte golpe en la cabeza, la luz, símbolo de la razón, se apaga y marca la entrada a un espacio ultramundano en el que Jean deberá reconducir su relación con el muerto y redirigir, desde la muerte, su relación con la vida y con los vivos. Jean, de hecho, vuelve a la vida al final de la obra, para descubrir que todos los personajes que la rodeaban han transformado sus hasta entonces anodinas existencias de un modo disparatado y también ella deberá hacerlo para querer a Dwight «mejor que todos los héroes» (Ruhl 2008: $98)^{4}$.

Estas son tan solo unas pinceladas que resumen superficialmente los entresijos de la segunda parte, pero permiten atisbar el modo en que la comedia de Ruhl se transforma de un acto a otro, de una cómica aunque melancólica transgresión de códigos y conductas sociales a una aventura fantástica, una cruzada moral, un viaje entre la vida y la muerte para llegar a un final feliz fraguado apresurada y alocadamente y ejemplo de ese hibridismo que desconcierta a algunos, fascina a otros y disgusta a quienes lo encuentran caprichoso. ¿Cómo interpretar estas súbitas e inesperadas transformaciones que acontecen en el espacio escénico?

\section{Sobre la recuperación de la poética de transformación teatral de la comedia}

Una lectura interesante de la metamorfosis de Dead Man's Cell Phone proviene de la directora del estreno mundial de la obra en Washington D.C. a cargo de la Wolly Mammoth Theatre Company, Rebecca Taichman, quien se refirió al texto como «extremadamente caprichoso» aunque después se «pudiera sentir que su volubilidad servía de contrapunto a una extrema alienación dando paso a algo naciente que lucha por sobrevivir» (Hart 2007). Es precisamente la alusión a 'aquello que nace' donde se ha de poner la atención crítica, pero no como resultado de una reacción una vez más calificada de caprichosa, sino más bien como una estrategia meditada, que podría ser sencillamente fruto del

4 El verso de John Donne evocado por Dwight al final de la obra y citado por la autora, hace referencia concretamente a los 'Nueve de la fama' (The Nine Worthies), aquellos personajes históricos, bíblicos o legendarios elegidos por haber encarnado los ideales de la caballería en la Edad Media. 
«cambio a un marco perceptivo anterior al siglo xx» (Vogel 2007) recurrente en la obra de Ruhl -tal y como apunta su mentora, la gran dramaturga Paula Vogel.

Hemos visto ya que uno de los modos de atestiguar relaciones intertextuales es a través de las citas, pero no es el único en Dead Man, pues la referencia metateatral articulada a través de nombrar a un personaje Hermia, la mujer de Gordon, conduce por supuesto hasta El sueño de una noche de verano, un intertexto que permite sugerir que las últimas escenas de la obra recuperan en el siglo Xxi la estructura de la comedia shakespeareana, denominada por Northrop Frye en The Anatomy of Criticism, como «the drama of the green world» (Frye 1973: 182). Este empieza en un mundo representado como el mundo normal, va hacia un mundo verde, se adentra allí en una metamorfosis en la que se alcanza una resolución cómica, para retornar nuevamente al mundo normal (Frye 1973: 182). En el caso que nos ocupa, no hay una entrada a un mundo mágico como es el reino de Oberón y Titania, sino una difuminación de las barreras entre el mundo de los vivos y el mundo de los muertos. Sin embargo, el final feliz alocadamente concebido demuestra que la comedia ilustra regularmente el triunfo de una trama arbitraria sobre la consistencia de los personajes; los finales felices, explica Frye (1973: 170)5, «no nos han de parecer verosímiles, sino deseables, y se producen a través de una manipulación. El espectador de la muerte y de la tragedia no puede más que permanecer sentado y esperar lo inevitable; pero algo nace al final de una comedia, y el espectador de un nacimiento es un miembro de una sociedad activa».

El modo en que la obra de Ruhl se transforma inesperadamente de un acto a otro podría ser entendido como una estrategia frívola de negar o escapar de aquello a lo que nos expone desde la primera escena: la finitud, la pérdida, el duelo, la soledad ${ }^{6}$. Sin embargo, lejos de ser considerada escapista ante la gravedad de la ineluctabilidad de la muerte y el misterio del otro, la obra debe ser valorada por lo que propone y lo que hace: actuar sobre dichas cuestiones con la disposición material, corporal y de maquinaria de una «operación extremadamente artesanal» (Badiou 1993: 20) como es el teatro. Este ofrece la posibilidad de que los muertos se reencarnen, y de favorecer -en este caso, a través de una catábasis y una anábasis- que encuentros imposibles fuera de un

5 La recuperación de la memoria de antiguas formas teatrales como la estructura de la comedia shakespeareana no es sorprendente cuando Ruhl ha escrito, en el ensayo recogido en el libroThe Play that Changed my life, que entre las obras que más han influido en su modo de entender el teatro se encuentra, precisamente, El Sueño de una noche de verano. Su madre dirigió una versión escolar ambientada en los años veinte, con flappers y gangsters, y verla representada una y otra vez hizo aflorar en la dramaturga un amor temprano por la transformación teatral a caballo entre lo culto y lo popular (Hodges 2009: 125).

6 Tanto Dead Man's Cell Phone como otras obras de Sarah Ruhl plantean complejas exploraciones de la muerte y de la necesidad de enfrentarse a ella para poder crear una verdadera comunidad, temas en los que en este artículo, por falta de espacio, no es posible ahondar. $C f$. Fernández-Caparrós (2015). 
escenario como la cita de Jean y Gordon en un más allá parecido a un café de autoservicio puedan tener lugar, sustentando así el convencimiento de Ruhl de que el teatro es esencialmente un ritual público de preparación para la muerte ${ }^{7}$. Y si atendemos de nuevo al complejo diálogo intertextual y de intermedialidad con Strand y Hopper, también aquí se puede sugerir que Dead Man responde desde el lenguaje dramático a la cuestión de la oscuridad de fondo y la sensación de encierro tomada de los cuadros de Hopper -que es, según Strand, un cuestionamiento sobre nuestro modo de afrontar el tiempo. La lectura del poeta de este elemento crucial de la de obra del pintor americano la encontramos precisamente alrededor de la cita elegida por Ruhl para anteceder el cuerpo del texto de Dead Man:

[Detrás de la pregunta por la importancia de esa oscuridad que produce una sensación de encierro, o al menos de limitación, en los cuadros de Hopper, se encuentra el cuestionamiento de nuestro modo de afrontar el tiempo: qué hacemos con él y qué hace él de nosotros.] En muchos cuadros de Hopper hay una espera aconteciendo. [La gente a la que Hopper pinta parece no tener nada que hacer.] Son como personajes que se hubiesen quedado sin un papel que desempeñar, y ahora, atrapados en el espacio de su espera, deben hacerse compañía, [sin lugar a donde ir, sin futuro] (Strand 2008: 57; mi énfasis).

Conocer lo que la autora omite del texto de Strand (indicado arriba entre corchetes) parece ser tan importante como lo que selecciona para ser transportado y anteceder la lectura de su texto dramático, pues si no cabe duda de que en Dead Man hay una trasposición inicial de esa suerte de soledad y parálisis de los cuadros de Hopper, la metamorfosis que se produce en el segundo acto parece revelar asimismo la respuesta dada tanto a lo citado como a lo descartado: una rebelión dramática para actuar al más puro estilo isabelino ante la falta de futuro, ante un modo de afrontar el tiempo marcado por la espera, ante ese aparente no tener nada que hacer, y ante una sociedad caracterizada por el desmembramiento ${ }^{8}$ (tropo que se extiende a la profesión de Gordon como comerciante de órganos), para construir acaso un futuro, un porvenir, algo naciente, una comunidad con los ausentes.

\section{Oda a la levedad}

Interpretar la obra de Ruhl a la luz de otros textos y desde su diálogo con ellos es, creo haber mostrado, no necesariamente un modo de fijar el sentido del texto sino -al ampliar, complicar y difuminar sus contextos- una estrategia idónea para comprender mejor su peculiar estrategia de hibridación de formas clásicas en un contexto contemporáneo. En este sentido, es necesario destacar, por último, inevitablemente, la recuperación a la que asistimos, también,

7 Cf. «Theatre as a preparation for Death» (Ruhl 2013).

8 En un ulterior juego intertextual y polisémico con la palabra part de la cita de Strand, traducida como 'papel', aunque podría ser 'parte'. 
de la polivalencia y multifuncionalidad de los objetos del teatro isabelino para convertir un teléfono móvil en el verdadero protagonista de la obra. En suspensión entre su utilidad instrumental y su uso imaginativo, el teléfono que da título a la obra y revelando la estructura del mundo que representa se convierte en un objeto móvil en el sentido literal del término: más que un objeto usado para la (tele)comunicación, sobre las tablas es un ente casi mágico, en un ente casi mágico, propio de un romance, destinado a viajar y transportar a quien lo porta hacia ámbitos y aventuras inesperadas.

La reivindicación del ilusionismo escénico es un componente fundamental de una poética teatral resuelta a transgredir las convenciones dramáticas del realismo, deshacer su sesgo mimético y abrir y tomar el espacio escénico más allá de los límites materiales de lo cotidiano. Y un modo idóneo, por otra parte, de llevar a cabo otra importantísima trasposición escénica, la de una filosofía defendida por Ruhl en varias ocasiones: la primera de las seis propuestas para el nuevo milenio que Italo Calvino formuló justo antes de morir, en 1985, en las que habrían sido sus Charles Eliot Norton Poetry Lectures de la universidad de Harvard, jamás pronunciadas, pero sí publicadas póstumamente. Me refiero, por supuesto, a la levedad.

La sustracción de peso en la escena teatral que propone la obra de Ruhl debe considerarse una estrategia de rebelión ante una tradición escénica que cuantas más cosas provenientes del mundo real introduce en el espacio escénico llamando la atención sobre sí mismas, más se aleja de la otredad a la que quiere llegar el ilusionismo escénico. No es osado sospechar que en esta elección haya un deseo de alejarse de las convenciones dramáticas más ensalzadas en el teatro norteamericano en las últimas décadas del siglo $\mathrm{xx}$, dominado por autores y por figuras masculinas en escenarios invadidos por objetos sin valor, por la hegemonía lingüística y por la violencia y el conflicto sin resolución: basta pensar en las escenografías y en las tramas de obras emblemáticas como American Buffalo (1975), de David Mamet, True West (1980), de Sam Shepard, o Hurlyburly (1984), de David Rabe, para comprender que los sucintos diálogos de Ruhl y una escenografía en la que se ha suprimido toda utilería superflua para llegar a lo esencial suponen, inevitablemente, una reacción discreta aunque vigorosa a esas poéticas teatrales.

La obra dramática de Sarah Ruhl no es, en conclusión, una obra transgresora que pretenda desprenderse de las convenciones temporales del drama del modo en que lo hace el teatro post-dramático reclamando lo episódico, frente a la linealidad de las tramas, o la incertidumbre epistemológica, frente a la capacidad material de lo escénico de significar por sí misma (Barnett 2008: 15). El éxito de su clasicismo paladino y sus afinidades electivas pueden resultar sorprendentes en un país enamorado del progreso y con la mirada siempre puesta hacia el futuro, pero también ponen de manifiesto la aceptación, la necesidad, el anhelo en la escena norteamericana contemporánea de dar paso a otras voces, otros ámbitos, vías múltiples, y tal vez, a más teatro escrito por mujeres. 


\section{Bibliografía}

Al-Shamma J., 2011, Sarah Ruhl: A Critical Study of her Plays, Jefferson, NC, Macfarland \& Co.

Atkis Durham L., 2013, Women's Voices on American Stages in the Early TwentyFirst Century: Sarah Ruhl and Her Contemporaries, New York, Palgrave Macmillan.

Badiou A., 1993, Rapsodia por el teatro, traducción de E. Arauxo y L. Martul, Málaga, Ágora.

Barnett D., 2008, «When is a play not a drama? Two examples of Postdramatic Theatre Texts», New Theatre Quarterly 24, p. 14-23.

Bogart A. y Fernández-Caparrós A., 2013, «On Directing Sarah Ruhl», entrevista inédita.

Calvino I., 1993, Lezioni Americane: Sei proposte per il prossimo millennio, Milano, Mondadori.

Dickens Ch., 1951, Historia de dos ciudades, in: Obras Completas, tomo II, Traducción, ensayo biográfico y notas de José Méndez Herrera, Madrid, Aguilar.

Donne J., 1996, Canciones y sonetos, Edición bilingüe de Purificación Ribes, Madrid, Cátedra.

Fernández-Caparrós A., 2015, «Death and the Community of Comic Romance: Sarah Ruhl's Poetics of Transformation in Dead Man's Cell Phone», Contemporary Theatre Review 25.4, p. 488-501, http://www.tandfonline.com/ doi/pdf/10.1080/10486801.2015.1078324

Frye N., 1973 [1957], Anatomy of Criticism: Four Essays, Princeton, Princeton University Press.

Goodman L., 2007, «Poet Laureate of Grief, Brown Alumni Magazine, AprilMarch, http://www.brownalumnimagazine.com/content/view/288/40/.

Hart S., 2007, «Rebecca Baila Taichman: Popping Like Fireworks», American Theatre, October Issue, http://www.tcg.org/publications/at/oct07/taichman. cfm.

Hodges B. (ed.), 2009, The play that changed my life, Milwaukee, Applause Theatre and Cinema Books.

Jonas S. y Bennet S., 2002, «Report on the Status of Women: a Limited Engagement?», www.womenarts.org

Lahr J., «Surreal Life», 2008, The New Yorker, March 17 http://www.newyorker. com/arts/critics/atlarge/2008/03/17/080317crat_atlarge_lahr?printable $=$ true\&currentPage $=$ all

Mamet D., 1987, American Buffalo, London, Methuen.

Norman M., 2009, «Not There Yet: What will take to achieve equality for women in the theatre?», American Theatre, November Issue, http://www.tcg.org/ publications/at/nov09/women.cfm

Orr M., 2003, Intertextuality: Debates and Contexts, Cambridge, Polity Press. 
Rabe D., 1985, Hurlyburly: A Play, New York, Grove Press.

Rainer A., 2006, Ghosts: Death's Double and the phenomena of Theatre, Minneapolis, London, University of Minnesota Press.

Ruhl S., 2006, The Clean House and Other Plays, New York, Theatre Communications Group.

Ruhl S., 2008, Dead Man's Cell Phone, New York, Theatre Communications Group.

Ruhl S., 2009, «Ten Essays by Sarah Ruhl», The Dramatist, Sept., p. 42-45.

Ruhl S., 2013, Seventy-five essays I don't have time to write, http://www. sarahruhlplaywright.com/essays/view/.

Shakespeare W., 2012, El sueño de una noche de verano, edición bilingüe de Manuel A. Conejero, Madrid, Cátedra.

Shepard S., 1981, True West, London, Faber and Faber.

Strand M., 2008, Hopper, traducción y prólogo de Juan Antonio Montiel, Barcelona, Lumen.

Vogel P., 2007, «Sarah Ruhl», Bomb Magazine 99, Spring, p. 1-10, bombsite.com/ issues/99/articles/2902. 